Jurnal Qua Teknika, Vol. 8 No. 1 Maret 2018

p-ISSN: 2088-2424; e-ISSN: 2527-3892

Fakultas Teknik Universitas Islam Balitar, Blitar

Http://qua.unisbablitar.ejournal.web.id; Email: quateknika@Gmail.com

Tri Hartanto dan Achendri M. Kurniawan. 2018. Perhitungan struktur dan volume bangunan abutment jembatan beton (Studi Kasus Jembatan Beton Bertulang di Desa Jolosutro Blitar).

Jurnal Qua Teknika, (2018), 8 (1) : 1-10

\title{
PERHITUNGAN STRUKTUR DAN VOLUME BANGUNAN ABUTMENT JEMBATAN BETON BERTULANG ( Studi Kasus Jembatan Beton Bertulang di Desa Jolosutro Blitar )
}

\author{
Tri Hartanto, Achendri M. Kurniawan \\ Program Studi Teknik Sipil Fakultas Teknik, Universitas Islam Balitar \\ Jl. Majapahit No. 4 Blitar Jawa Timur \\ Email : achendri.m.kurniawan@unisbablitar.ac.id
}

\begin{abstract}
ABSTRAK
Bridges are important to everyone (Supriyadi, 2007). But the level of importance is not the same for everyone, so it will be an interesting study material. A single bridge over a small river will be viewed differently by everyone, because the visions or views of each person who sees differently.

Indonesia is one of the developing countries that is active in implementing development in all fields. Along with developing highway transportation technology, bridge construction must be planned in accordance with the demands of transportation both in terms of speed, convenience, and security. In the construction of highway bridges with short spans, reinforced concrete construction should be used as the main girder. Given that in the years to come the government is still building road bridges with short spans to connect areas with one another and to date this type of reinforced concrete construction is a good type of construction to be applied to the construction of short-span bridges.
\end{abstract}

Keywords: Structure, Bridge, reinforced concrete, abutment building volume, short span.

Jembatan mempunyai arti penting bagi setiap orang(Supriyadi, 2007). Akan tetapi tingkat kepentingannya tidak sama bagi tiap orang, sehingga akan menjadi sebuah bahan studi yang menarik. Suatu jembatan tunggal diatas sungai kecil akan dipandang berbeda oleh setiap orang, sebab penglihatan atau pandangan masing - masing orang yang melihat berbeda pula.

Indonesia adalah salah satu negara berkembang yang sedang giat malaksanakan pembangunan di segala bidang. Seiring dengan berkembang teknologi angkutan jalan raya maka konstruksi jembatan harus direncanakan sesuai dengan tuntutan transportasi baik dari segi kecepatan, kenyamanan, maupun keamanan. Pada pembangunan jembatan jalan raya dengan bentang pendek, sebaiknya digunakan konstruksi beton bertulang sebagai gelagar utama. Mengingat dalam tahun-tahun mendatang pemerintah masih membangun jembatan-jembatan jalan raya dengan bentang yang pendek untuk menghubungkan daerah satu dengan daerah yang lain dan sampai saat ini jenis konstruksi beton bertulang merupakan jenis konstruksi yang baik untuk diterapkan pada pembangunan jembatan dengan bentang yang pendek.

Kata Kunci: Struktur, Jembatan, beton bertulang, volume bangunan abutment, bentang pendek.

Penelitian ini untuk mengetahui struktur bangunan bawah atau abutment jembatan beton bertulang dan untuk mengetahui volume penulangan besi dan beton pada bangunan abutment jembatan beton bertulang. Penentuan bentuk struktur jembatan ada di tahap perencanaan. Perencanaan jembatan harus sesuai peraturan yang berlaku. Berdasarkan perkembangan teknologi saat ini, peraturan perencanaan yang dapat digunakan perencana adalah peraturan perencanaan jembatan dari BMS 1992, SNI T-02-2005, SNI T-12-2004, dan SNI 2833:2008. Bagian- bagian utama jembatan adalah sebagai berikut: Bangunan Atas Jembatan (upper stucture) yang terdiri dari Tiang sandaran, Trotoar, Lantai Trotoar, Lantai Kendaraan, Balok Diafragma, dan Gelagar. Sedangkan Bangunan Bawah Jembatan terdiri dari Kepala jembatan (Abutment), Plat injak, Pondasi. Pelaksanaan praktikum bertempat di desa Jolosutro Kecamatan Wates Kabupaten Blitar. Pelaksanaan praktik pada tanggal 16 Juni 2017 sampai dengan 15 Juli 2017. Jembatan di dibangun dijalan yang menghubungkan desa setempat, terbentang panjang $6 \mathrm{~m}$ dengan lebar $4 \mathrm{~m}$ diatas anak sungai dengan ketinggian $3 \mathrm{~m}$ diatas permukaan air sungai. Jembatan ini didesain dan sudah dianalisa struktur oleh konsultan CV. Kusuma Abadi dan dikerjakan oleh CV. Bela Negara selaku kontraktor terpilih.

Penelitian ini bertujuan untuk mengetahui struktur bangunan bawah atau abutment jembatan beton bertulang dan volume penulangan besi dan beton pada bangunan abutment jembatan beton bertulang. Sebelum pengujian dilaksanakan, dilakukan pengumpulan data primer dan data sekunder terlebih dahulu. Setelah itu dilakukan survey lapangan dan perencanaan konstruksi jembatan diperlukan data-data yang digunakan sebagai 
Jurnal Qua Teknika, Vol. 8 No. 1 Maret 2018

p-ISSN: 2088-2424; e-ISSN: 2527-3892

Fakultas Teknik Universitas Islam Balitar, Blitar

Http://qua.unisbablitar.ejournal.web.id; Email: quateknika@ Gmail.com

Tri Hartanto dan Achendri M. Kurniawan. 2018. Perhitungan struktur dan volume bangunan abutment jembatan beton (Studi Kasus Jembatan Beton Bertulang di Desa Jolosutro Blitar).

Jurnal Qua Teknika, (2018), 8 (1) : 1-10

dasar perencanaan. Survey perlu dilaksanakan dengan cermat sehingga akan diperoleh data yang akurat. Menurut RSNI T-12-2004, Perencanaan harus berdasarkan pada suatu prosedur yang memberikan jaminan keamanan pada tingkat yang wajar, berupa kemungkinan yang dapat diterima untuk mencapai suatu keadaan batas selama umur rencana jembatan. Perencanaan kekuatan balok, pelat, kolom beton bertulang sebagai komponen struktur jembatan yang diperhitungkan terhadap lentur, geser, lentur dan aksial, geser dan puntir, harus didasarkan pada cara Perencanaan berdasarkan Beban dan Kekuatan Terfaktor (PBKT). Untuk perencanaan komponen struktur jembatan yang mengutamakan suatu pembatasan tegangan kerja, seperti untuk perencanaan terhadap lentur dari komponen struktur beton prategang penuh, atau komponen struktur lain sesuai kebutuhan perilaku deformasinya, atau sebagai cara perhitungan alternatif, dapat digunakan cara Perencanaan berdasarkan Batas Layan (PBL). Di samping itu, perencanaan harus memperhatikan faktor integriti komponenkomponen struktur maupun keseluruhan jembatan, dengan mempertimbangkan faktor-faktor berikut:

1. Kontinuitas dan redundansi.

2. Semua komponen struktur jembatan harus mempunyai ketahanan yang terjamin terhadap kerusakan dan instabilitas sesuai umur jembatan yang direncanakan.

3. Aspek perlindungan eksternal terhadap kemungkinan adanya beban yang tidak direncanakan atau beban berlebih

Data Sekunder didapatkan dari instansi terkait, dalam penelitian ini yaitu dinas PU Kabupaten Blitar dan CV. Kusuma Abadi selaku konsultan proyek jembatan di desa Jolosutro. Data tersebut antara lain : Studi Literatur, Data Tanah, Data Curah Hujan, Data Pendukung Lain, Gambar Kerja Jembatan, Spesifikasi bangunan abutment, Spesifikasi konstruksi, Data jenis dan kualitas beton yang digunakan. Untuk penunjang menganalisis struktur jembatan terutama struktur beton abutmen, diperlukan data-data perencanaan dan pedoman peraturan - peraturan tentang jembatan yang telah ditetapkan oleh pemerintah sebagai berikut : RSNI T01-2005 tentang Standar Pembebanan Untuk Jembatan, Pedoman Perencanaan Pembebanan Jembatan Jalan Raya SKBI 1.3.28. 1987 Udl : 624.042.624.21, Peraturan muatan untuk Jembatan Jalan Raya No. 12/1970, Peraturan Beton Bertulang Indonesia NI-2. 1971, Serta buku - buku lain yang dapat menunjang dalam penyelesaian tugas akhir ini.

\section{METODE PENELITIAN}

Adapun prosedur penelitian sebagai berikut :

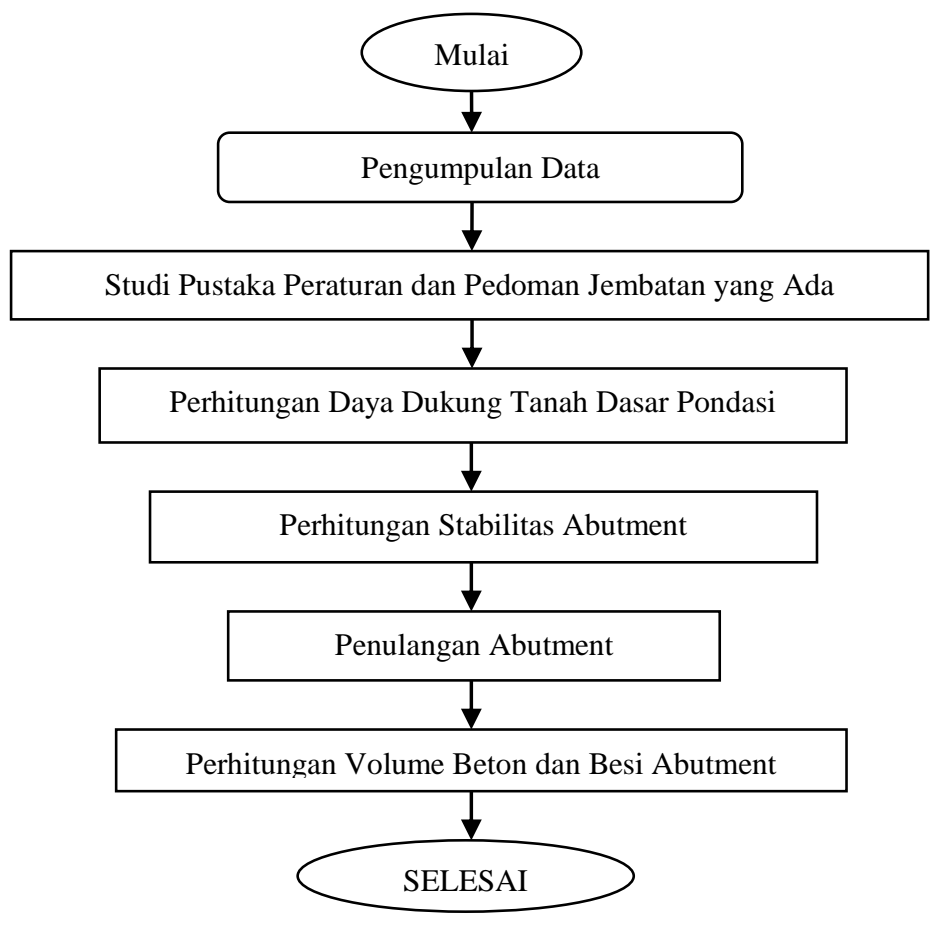

Perhitungan gaya - gaya yang bekerja pada abutment: 
Tri Hartanto dan Achendri M. Kurniawan. 2018. Perhitungan struktur dan volume bangunan abutment jembatan beton (Studi Kasus Jembatan Beton Bertulang di Desa Jolosutro Blitar). Jurnal Qua Teknika, (2018), 8 (1):1-10

a. Gaya akibat beban mati

Gaya Horisontal akibat gesekan tumpuan bergerak $(\mathrm{Hg})$

Koefisien gesekan $=0,25($ PPPJJR $/ 1987$ pasal 2.6.2)

Hgesekan = koefisien gesekan . Rvd

$\mathrm{RVD}=\frac{\mathrm{P} \text { total }}{2}=\ldots \ldots . .$. ton

b. Gaya akibat muatan hidup

$\mathrm{Rq}_{\mathrm{L}}=\frac{\mathrm{q}}{2,75} x l=\ldots \ldots$....ton

Koefisien kejut $=1+$ ton

Gaya akibat rem dan traksi

Diperhitungkan $5 \%$ dari beban $\mathrm{D}$ tanpa koefisien kejut dengan titik tangkap 1,8 $\mathrm{m}$ diatas permukaan lantai kendaraan ( PPPJJR / 1987 hal 15).

traksi Rrt $=\frac{5 \% \times(\mathrm{RPL}+\mathrm{Rql})}{2}=\ldots$..ton

c. Gaya gempa akibat bangunan atas

$\mathrm{K}=$ ketetapan $(0,07)$

$\mathrm{GI}=\mathrm{K} \cdot \mathrm{Rvd}$

Gaya horizontal tanah :

$\mathrm{Ka}=\operatorname{tg}^{2}\left(45^{0}-\frac{\phi}{2}\right)$

$\mathrm{Kp}=\operatorname{tg}^{2}\left(45^{0}-\frac{\phi}{2}\right)$

$\mathrm{Pa} 1=\mathrm{Ka} \cdot \mathrm{q} \cdot \mathrm{h}_{1} \cdot \mathrm{b}$

Pa $2=1 / 2 \cdot \mathrm{Ka} \cdot \gamma_{1} \cdot \mathrm{h}_{1}^{2} \cdot \mathrm{b}$

$\mathrm{Pp}=1 / 2 \cdot \mathrm{Kp} \cdot \gamma_{1} \cdot \mathrm{h}^{2} \cdot \mathrm{b}$

d. Hitungan daya dukung tanah dasar pondasi

$\varphi=\operatorname{arctg}(\operatorname{Kr} \varphi \cdot \tan \varphi) \quad$ SNI $03-3446-1994$, halaman $8-9$. Daya dukung tanah dasar

pondasi berdasarkan rumus tarzhagi untuk pondasi persegi pada kondisi tanah $\mathrm{C}=3,1 \mathrm{t} / \mathrm{m}^{2}$

$\mathrm{Qult}=\mathrm{C} \cdot \mathrm{Nc}+\mathrm{D} \cdot \gamma_{1} \cdot \mathrm{Nq}+0,5 \cdot \mathrm{B} \cdot \gamma_{2} \cdot \mathrm{N} \gamma$

$\mathrm{Q}_{\text {all }}=\frac{\text { Qult }}{\mathrm{SF}}$

e. Perhitungan stabilitas abutment

Syarat perhitungan aman :

$\mathrm{SF}=\frac{\sum V \cdot \tan \frac{2}{3} \Phi^{\circ}+c \cdot B}{\sum \mathrm{H}}$

Syarat aman terhadap guling :

$\mathrm{SF}=\frac{\sum \mathrm{M} x}{\sum \mathrm{My}}$

Syarat aman terhadap eksentrisitas

$\mathrm{e}=\frac{B}{2}-\frac{\sum \mathrm{M} x-\sum \mathrm{My}}{\sum \mathrm{V}}<\frac{B}{6}$

f. Penulangan abutment

Batas - batas penulangan pada abutment menggunakan rumus yang sama seperti penulangan di bawah ini : 
Tri Hartanto dan Achendri M. Kurniawan. 2018. Perhitungan struktur dan volume bangunan abutment jembatan beton (Studi Kasus Jembatan Beton Bertulang di Desa Jolosutro Blitar). Jurnal Qua Teknika, (2018), 8 (1): 1-10

$$
\begin{aligned}
& \text { pbln }=\left(\frac{0.85 \cdot \beta 1 \cdot f^{\prime} c}{f y}\right) \times\left(\frac{600}{600+f y}\right) \\
& \rho \max =0,75 \times \rho b l n \\
& \rho \min =\frac{1,4}{f y \times \frac{1,4}{f y}} \\
& \mathrm{~m}=\frac{f y}{0,85 \times f c} \\
& \operatorname{Rn} \quad=\frac{M n}{b \cdot d^{2}} \\
& \rho_{\text {perlu }} \quad=\frac{1}{m}\left(1-\sqrt{1-\left(\frac{2 \cdot m \cdot R n}{f y}\right)}\right)
\end{aligned}
$$

Luas tulangan :

As $=\rho_{\min } . \mathrm{bd}$

As bagi $=20 \%$. As pokok

Kontrol tulangan geser

$$
\begin{aligned}
& \mathrm{Vc}=\left(\frac{1}{6} \sqrt{f^{\prime} c}\right) \cdot b \cdot d \\
& \phi . \mathrm{Vc}<\mathrm{Vu}<3 . \phi \cdot \mathrm{Vc} \\
& \mathrm{Vs}_{\text {perlu }} \quad=\frac{V u-\phi \cdot V c}{\phi}
\end{aligned}
$$

As v $=2 \cdot 1 / 4 \cdot \mathrm{pi} \cdot \mathrm{d}^{2}$

$\mathrm{s}=\frac{A s v \cdot f y \cdot d}{V s}$

Jarak sengkang maksimum tulangan geser :

$\operatorname{Smax}=\frac{d}{2}$

$$
\mathrm{Vs}_{\mathrm{ada}}=\frac{A s v \cdot f y \cdot d}{V s}
$$

\section{HASIL DAN PEMBAHASAN}

Tinjauan Dimensi Abutment

Rencana dimensi abutment dapat dilihat pada gambar berikut : 
Tri Hartanto dan Achendri M. Kurniawan. 2018. Perhitungan struktur dan volume bangunan abutment jembatan beton (Studi Kasus Jembatan Beton Bertulang di Desa Jolosutro Blitar). Jurnal Qua Teknika, (2018), 8 (1) : 1-10

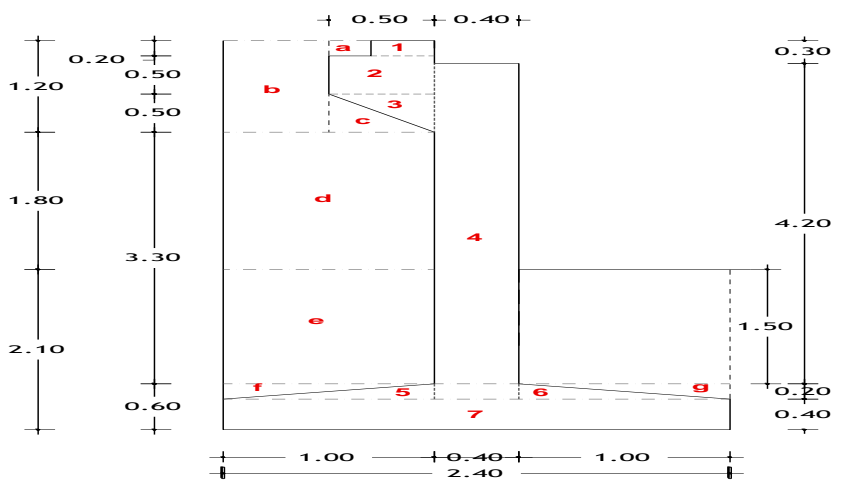

Gambar 4.1. Dimensi Abutment

a. Beban mati

$>$ Lantai kendaraan

$>$ Air hujan $3 \mathrm{~cm}$

$>$ Aspal $7 \mathrm{~cm}$

$>$ Pipa sandaran

$>$ Tiang sandaran

$>$ Beban tak terduga

\begin{tabular}{|c|c|}
\hline$: 0,3.9+6) / 2.4 .2,5$ & $=22,5$ \\
\hline :0,03 . $(9+6) / 2.4 .1,0$ & $=0,9$ \\
\hline$: 0,07 .(9+6) / 2.4 \cdot 2,2$ & $=4,62$ \\
\hline$: 4.0,0009085 \cdot 9 \cdot 7,13$ & $=0,233$ \\
\hline : $9.0,1.0 .15 .1 .2,5$ & $=0,337$ \\
\hline : & $=5$ \\
\hline
\end{tabular}

$\mathrm{RVD}=\frac{33,6}{2}=16,795$ ton

b. Beban hidup

Muatan hidup $\mathrm{P}_{\mathrm{L}}=12$ ton , $\mathrm{q}_{\mathrm{L}}=2,2 \mathrm{t} / \mathrm{m}$

Lebar jalur lalu lintas $=6 \mathrm{~m}$

$$
\begin{aligned}
& \text { Koefisien kejut }=1+\frac{20}{50+\mathrm{L}}=1+\frac{20}{50+6}=1,357 \text { ton } \\
& \begin{aligned}
\mathrm{R}_{\mathrm{qL}} & =\frac{q}{2,75} \times 1=\frac{2,2}{2,75} \times 6=4,8 \text { ton } \\
\mathrm{R}_{\mathrm{PL}} & =\frac{q}{2,75} \times \mathrm{k} \times 1=\frac{12}{2,75} \times 1,344 \times 6=35,532 \mathrm{ton} \\
\mathrm{R}_{\mathrm{VL}} & =\mathrm{k} \times \mathrm{RPL}+\left(\frac{1}{2} \times \mathrm{RqL}\right) \\
& =1,357 \times 35,532+\left(\frac{1}{2} x 4,8\right) \\
& =50,617 \text { ton }
\end{aligned}
\end{aligned}
$$

Analisa tampang abutment dan tekanan tanah

1. Badan abutment

Tabel 4.1.Hitungan titik berat badan abutment

\begin{tabular}{|c|c|c|c|c|c|}
\hline \multirow{2}{*}{ Segmen } & \multirow{2}{*}{ Luas segmen $\left(\mathrm{m}^{2}\right)$} & \multicolumn{2}{|c|}{ Lengan terhadap $\mathrm{O}$} & \multirow{2}{*}{ Mx $=$ Ac.x } & \multirow{2}{*}{ My $=$ Ac.y } \\
\cline { 3 - 4 } & & $\mathrm{X}(\mathrm{m})$ & $\mathrm{Y}(\mathrm{m})$ & & \\
\hline 1 & 0,06 & 1,55 & 5,00 & 0,093 & 0,300 \\
\hline 2 & 0,25 & 1,64 & 4,66 & 0,410 & 1,165 \\
\hline 3 & 0,125 & 1,57 & 4,23 & 0,196 & 0,529 \\
\hline 4 & 1,76 & 1,20 & 2,60 & 2,112 & 4,576 \\
\hline 5 & 0,10 & 1,73 & 0,47 & 0,173 & 0,047 \\
\hline 6 & 0,10 & 0,67 & 0,47 & 0,067 & 0,047 \\
\hline 7 & 0,96 & 1,20 & 0,20 & 1,152 & 0,192 \\
\hline$\Sigma A c$ & 3,355 & & & 4,203 & 6,856 \\
\hline
\end{tabular}


Tri Hartanto dan Achendri M. Kurniawan. 2018. Perhitungan struktur dan volume bangunan abutment jembatan beton (Studi Kasus Jembatan Beton Bertulang di Desa Jolosutro Blitar). Jurnal Qua Teknika, (2018), 8 (1) : 1-10

Jarak dari titik 0 terhadap pusat berat adalah :

$$
\begin{aligned}
& \mathrm{Xc}=\frac{\sum M x}{\sum \mathrm{Ac}}=\frac{4,203}{3,355}=1,253 \mathrm{~m} \\
& \mathrm{Yc}=\frac{\sum M y}{\sum \mathrm{Ac}}=\frac{6,856}{3,355}=2,043 \mathrm{~m}
\end{aligned}
$$

2. Tanah di samping abutment

Tabel 4.2.Hitungan titik berat tanah di belakang abutment

\begin{tabular}{|c|c|c|c|c|c|}
\hline \multirow{2}{*}{ Segmen } & \multirow{2}{*}{ Luas segmen $\left(\mathrm{m}^{2}\right)$} & \multicolumn{2}{|c|}{ Lengan terhadap 0 } & \multirow{2}{*}{ Mx = Ac.x } & \multirow{2}{*}{ My = Ac.y } \\
\cline { 3 - 4 } & & $\mathrm{X}(\mathrm{m})$ & $\mathrm{Y}(\mathrm{m})$ & & \\
\hline A & 0,04 & 1,80 & 5,00 & 0,072 & 0,200 \\
\hline B & 0,6 & 2,15 & 4,50 & 1,290 & 2,700 \\
\hline C & 0,125 & 1,80 & 4,07 & 0,225 & 0,509 \\
\hline D & 1,8 & 1,90 & 3,00 & 3,420 & 5,400 \\
\hline E & 1,50 & 1,90 & 1,35 & 2,850 & 2,025 \\
\hline F & 0,10 & 2,07 & 0,53 & 0,207 & 0,053 \\
\hline$\Sigma A t$ & 4,165 & & & 8,064 & 10,887 \\
\hline
\end{tabular}

Jarak dari titik 0 terhadap pusat geometri adalah :

$$
\begin{aligned}
\mathrm{Xt}_{1} & =\frac{\sum M x}{\sum \mathrm{At} 1}=\frac{8,064}{4,165}=1,936 \mathrm{~m} \\
\mathrm{Yt}_{1} & =\frac{\sum M y}{\sum \mathrm{At} 1}=\frac{10,887}{4,165}=2,614 \mathrm{~m}
\end{aligned}
$$

\begin{tabular}{|c|c|c|c|c|c|}
\hline \multirow{2}{*}{ Segmen } & \multirow{2}{*}{ Luas segmen $\left(\mathrm{m}^{2}\right)$} & \multicolumn{2}{|c|}{ Lengan terhadap 0} & \multirow{2}{*}{$M x=A c \cdot x$} & \multirow{2}{*}{$\mathrm{My}=\mathrm{Ac} \cdot \mathrm{y}$} \\
\hline & & $\mathrm{X}(\mathrm{m})$ & $\mathrm{Y}(\mathrm{m})$ & & \\
\hline G & 0,10 & 0,33 & 0,53 & 0,033 & 0,053 \\
\hline $\mathrm{H}$ & 1,50 & 0,50 & 1,35 & 0,750 & 2,025 \\
\hline$\Sigma A t$ & 1,60 & & & 0,783 & 2,078 \\
\hline
\end{tabular}

Table 4.3. Hitungan titik berat tanah di depan abutment

Jarak dari titik 0 terhadap pusat berat adalah :

$$
\begin{aligned}
\mathrm{Xt}_{2} & =\frac{\sum M x}{\sum \mathrm{At} 2}=\frac{0783}{1,60}=0,489 \mathrm{~m} \\
\mathrm{Yt}_{2} & =\frac{\sum M y}{\sum \mathrm{At} 2}=\frac{2,078}{1,60}=1,299 \mathrm{~m}
\end{aligned}
$$

Gaya - gaya yang berkerja pada abutment dapat dilihat pada gambar dibawah: 
Tri Hartanto dan Achendri M. Kurniawan. 2018. Perhitungan struktur dan volume bangunan abutment jembatan beton (Studi Kasus Jembatan Beton Bertulang di Desa Jolosutro Blitar). Jurnal Qua Teknika, (2018), 8 (1):1-10

Gambar 4.2. Gaya - gaya yang berkerjapada abutment

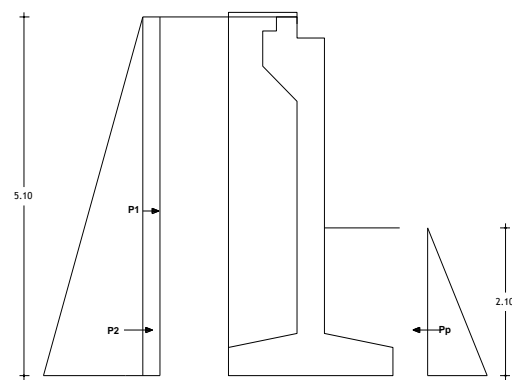

3. Tekanan tanah

Data tanah diperoleh dari konsultan Bina Marga Blitar. Data tanah tersebut dianggap dapat mewakili keadaan tanah dilokasi tinjauan jembatan ini.

a. Hitungan koefisien tekanan tanah

$$
\begin{aligned}
& \mathrm{Ka}=\operatorname{tg}^{2}\left(45^{0}-\frac{\phi}{2}\right) \\
& \mathrm{Ka}=\operatorname{tg}^{2}\left(45^{0}-\frac{35}{2}\right)=0,265 \mathrm{t} \\
& \mathrm{Kp}=\operatorname{tg}^{2}\left(45^{0}+\frac{\phi}{2}\right) \\
& \mathrm{Kp}=3,65 \mathrm{t}
\end{aligned}
$$

b. Tekanan tanah aktif $(\mathrm{Pa})$

$$
\begin{aligned}
\mathrm{Pa} 1 & =\mathrm{Ka} \cdot \mathrm{q} \cdot \mathrm{h}_{1} \cdot \mathrm{b} \\
& =0,265 \cdot 2,2 \cdot 5,1 \cdot 6=17,84 \mathrm{t} \\
\mathrm{Pa} 2 & =1 / 2 \cdot \mathrm{Ka} \cdot \gamma_{1} \cdot \mathrm{h}_{1}^{2} \cdot \mathrm{b} \\
& =1 / 2 \cdot 0,265 \cdot 1,7008 \cdot 5,10^{2} \cdot 6=35,17 \mathrm{t}
\end{aligned}
$$

c. Tekanan tanah pasif $(\mathrm{Pp})$

$$
\begin{aligned}
\mathrm{Pp} & =1 / 2 \cdot \mathrm{Kp} \cdot \gamma_{1} \cdot \mathrm{h}^{2} \cdot \mathrm{b} \\
& =1 / 2 \cdot 3,65 \cdot 1,7008 \cdot 2,10 \cdot 6=82,13 \mathrm{t}
\end{aligned}
$$

4. Hitungan daya dukung tanah dasar pondasi

Keadaaan lapisan tanah untuk pondasi dapat dilihat pada gambar dibawah ini :

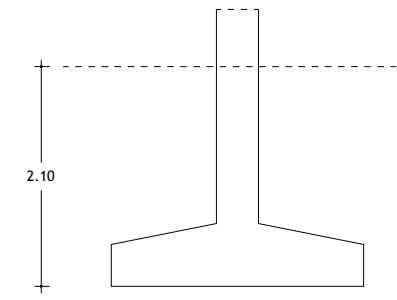

Gambar 4.3. Keadaan Lapisan Tanah Pondasi

Data tanah pada lapisan 3 dengan $\phi=35^{\circ}$ akan didapat

$$
\begin{aligned}
\Phi & =\operatorname{arctg}(\operatorname{Kr} \varphi \cdot \tan \varphi) \text { SNI } 03-3446-1994, \text { halaman } 8-9 \\
& =\operatorname{arctg}\left(0.7 \cdot \tan 35^{\circ}\right)=26,11^{0}
\end{aligned}
$$

Dari harga $\phi=26,11^{0}$ dengan table 4 (SNI $03-3446-1994$ ) akan diperoleh factor daya dukung $\mathrm{Nc}=22,25$;

$\mathrm{Nq}=13,75 ; \mathrm{N} \gamma=11,50$

Data pondasi :

Kedalamanpondasi $\mathrm{D}=2,10 \mathrm{~m}$, lebarpondasi $\mathrm{B}=2,40 \mathrm{~m}$

Daya dukung tanah dasar pondasi berdasarkan rumus tarzhagi untuk pondasi persegi pada kondisi $\operatorname{tanah} \mathrm{C}=3,1$ $\mathrm{t} / \mathrm{m}^{2}$ 
Tri Hartanto dan Achendri M. Kurniawan. 2018. Perhitungan struktur dan volume bangunan abutment jembatan beton (Studi Kasus Jembatan Beton Bertulang di Desa Jolosutro Blitar). Jurnal Qua Teknika, (2018), 8 (1) : 1-10

$$
\begin{aligned}
& \text { Qult } \begin{aligned}
\quad & \mathrm{C} \cdot \mathrm{Nc}+\mathrm{D} \cdot \gamma_{1} \cdot \mathrm{Nq}+0,5 \cdot \mathrm{B} \cdot \gamma_{2} \cdot \mathrm{N} \gamma \\
& =3,1 \cdot 22,25+2,10 \cdot 1,7008 \cdot 13,75+0,5 \cdot 2,40 \cdot 1,8236 \cdot 11,50 \\
& =143,25 \mathrm{t} / \mathrm{m}^{2}
\end{aligned} \\
& \text { Qall }=\frac{\text { Qult }}{\mathrm{SF}}=\frac{143,25}{3}=47,75 \mathrm{t} / \mathrm{m}^{2}
\end{aligned}
$$

Tabel 4.4.Gaya - gaya eksternal

\begin{tabular}{|c|c|c|c|c|c|c|}
\hline \multirow{2}{*}{ Gaya } & \multirow{2}{*}{$\mathrm{V}$ (ton) } & \multirow{2}{*}{$\mathrm{H}$ (ton) } & \multicolumn{2}{|c|}{ Lengan Momen } & $\mathrm{Mx}=\mathrm{V} . \mathrm{X}$ & $\mathrm{My}=\mathrm{H} . \mathrm{Y}$ \\
\cline { 4 - 7 } & & & $\mathrm{X}(\mathrm{m})$ & $\mathrm{Y}(\mathrm{m})$ & $\begin{array}{c}\text { Momen } \\
\text { Penahan tm }\end{array}$ & $\begin{array}{c}\text { Momen } \\
\text { Guling tm }\end{array}$ \\
\hline $\mathrm{Rv}$ & 57,13 & & 1,2 & & 68,553 & \\
\hline $\mathrm{Wc}$ & 50,33 & & 1,25 & & 63,049 & \\
\hline $\mathrm{Wt}_{1}$ & 42,50 & & 1,94 & & 82,292 & \\
\hline $\mathrm{Wt}_{2}$ & 16,33 & & 0,49 & & 7,990 & \\
\hline $\mathrm{Rr}$ & & 1 & & 5,1 & & 5,10 \\
\hline $\mathrm{Gg}$ & & 4,20 & & 4,9 & & 20,57 \\
\hline $\mathrm{Pa}_{1}$ & & 17,84 & & 2,55 & & 45,49 \\
\hline $\mathrm{Pa}_{2}$ & & 35,17 & & 1,05 & & 36,93 \\
\hline & $\sum \boldsymbol{H}$ & $\mathbf{5 8 , 2 1}$ & & & & \\
\hline $\mathrm{Pp}$ & & 82,13 & & 1,30 & 106,67 & \\
\hline $\mathrm{Tb}$ & & 50 & & 2,55 & 127,5 & \\
\hline & $\sum \boldsymbol{V}$ & & & & $\sum \boldsymbol{M x}$ & $\sum \boldsymbol{M y}$ \\
& $\mathbf{1 6 6 , 2 8}$ & & & & $\mathbf{4 5 6 , 0 5 1}$ & $\mathbf{1 0 8 , 0 9 3}$ \\
\hline
\end{tabular}

Stabilitas terhadap geser dasar pondasi

$\sum \mathrm{V}=$ gaya vertical $=166,28$ ton

$\sum \mathrm{H}=$ gaya horizontal $($ diambiltekanantanahaktif $)=58,21$ ton

$$
\mathrm{SF}=\frac{\sum V \cdot \tan \frac{2}{3} \Phi^{\circ}+c \cdot B}{\sum \mathrm{H}}=\frac{166,28 \cdot \tan \frac{2}{3} 35^{\circ}+3,1 \cdot 2,4}{\sum \mathrm{H}}=1,481 \geq 1 \mathbf{O K E}
$$

Stabilitas terhadap guling dasar pondasi

$\sum \mathrm{Mx}=$ momen penahan $=456,051 \mathrm{tm}$

$\sum \mathrm{My}=$ momen guling $=108,093 \mathrm{tm}$

$\mathrm{SF}=\frac{\sum \mathrm{M} x}{\sum \mathrm{My}}=\frac{456,051}{108,093}=4,219 \geq 1 \mathbf{O K E}$

Stabilitas terhadap eksentritas (e)

$\mathrm{e}=\frac{B}{2}-\frac{\sum \mathrm{M} x-\sum \mathrm{My}}{\sum \mathrm{V}}<\frac{B}{6}=\frac{2,4}{2}-\frac{456,051-108,093}{166,28}<\frac{2,4}{6}=-0,829<0,4$

1. Penulangan Plat Sandung

Luas tulangan :

As $\quad=\rho_{\min } . \mathrm{b} \mathrm{d}$

$$
=0,00412.1000 .192=791,04 \mathrm{~mm}^{2}
$$

Dipakai tulangan pokok $\varnothing 16-250=1005,31 \mathrm{~mm}^{2}>$ As perlu

Tulangan bagi

As bagi $=20 \%$. As pokok $=20 \% .1005,31=201,012 \mathrm{~mm}^{2}$

Dipakai tulangan pokok $\emptyset 12-250=307,72 \mathrm{~mm}^{2}>$ As bagi (OKE)

a. Penulangan bagian bawah

Luas tulangan :

As $\quad=\rho \min . \mathrm{b} . \mathrm{d}$ 
Tri Hartanto dan Achendri M. Kurniawan. 2018. Perhitungan struktur dan volume bangunan abutment jembatan beton (Studi Kasus Jembatan Beton Bertulang di Desa Jolosutro Blitar). Jurnal Qua Teknika, (2018), 8 (1) : 1-10

$$
=0,00412 \cdot 1000 \cdot 442=1821,040 \mathrm{~mm} 2
$$

Dipakai tulangan pokok $\varnothing 16-250=1005,31 \mathrm{~mm} 2>$ As perlu

Tulangan bagi

As bagi $=20 \%$. As pokok $=20 \% .1005,31=201,012 \mathrm{~mm} 2$

Dipakai tulangan pokok $\varnothing 12-250=307,72 \mathrm{~mm} 2>$ As bagi $(\mathrm{OKE})$

Penggunaan dilapangan $\varnothing 16-125$ (OKE)

2. Penulangan Konsol

Luas tulangan :

As $\quad=\rho \min . \mathrm{bd}$ $=0,00412.1000 .437,5=902,50 \mathrm{~mm} 2$

Dipakai tulangan pokok $\emptyset 16-250=1005,31 \mathrm{~mm} 2>$ As perlu

Penggunaan dilapangan $\varnothing 16-200$ (OKE)

Tulangan bagi :

As bagi $=20 \%$. As pokok $=20 \% .1005,31=201,012 \mathrm{~mm} 2$

Dipakai tulangan pokok $\varnothing 12-250=307,72 \mathrm{~mm} 2>$ As bagi(OKE)

Penggunaan dilapangan $\emptyset 12-200$ (OKE)

3. Penulangan Tubuh Abutment

Kombinasi gaya pada tubuh abutment

$\mathrm{Mu} \quad=1,2 \cdot \mathrm{D}+1,6 \cdot \mathrm{L}+1,6 \cdot(\mathrm{Pa}+\mathrm{Pp})$

$=1,2.29,276+1,6 \cdot 1,480+1,6 .(2,624+4,563+6,984)$

$=60,172 \mathrm{tm}=60,172.10^{7} \mathrm{Nmm}$

Dipakai tulangan pokok $\phi 22-200=1899,70 \mathrm{~mm}^{2}$

As bagi $=20 \%$. As pokok $=379,94 \mathrm{~mm}^{2}$

Dipakai tulangan bagi $\phi 12-150=753,60 \mathrm{~mm}^{2}$

4. Penulangan Dasar Abutment

$\mathrm{Mu}=1,2 . \mathrm{Mdl}+1,6 . \mathrm{Mll}$

$$
=1,2 \cdot 4,654+1,6 \cdot 13,3=26,865 \cdot 10^{7} \mathrm{Nmm}
$$

$$
400+1000
$$

$\mathrm{Ht}=2=700 \mathrm{~mm}$

$\mathrm{p}=50 \mathrm{~mm} ; \phi=20 \mathrm{~mm} ; \mathrm{b}=1000 \mathrm{~mm} ; \varphi 0,8$

d' $\quad=h t-p-1 / 2 \phi=700-50-1 / 220=640 \mathrm{~mm}$

f'c $\quad=25 \mathrm{Mpa} ; \mathrm{fy}=340 \mathrm{Mpa}$, Sehingga didapat :

$\mathrm{Mn}=\frac{M u}{\varphi}=\frac{26,865 \cdot 10^{7}}{0,8}=33,581 \cdot 10^{7}$

Rn $\quad=\frac{M n}{b \cdot d^{2}}=\frac{33,581 \cdot 10^{7}}{1000 \cdot 640^{2}}=0,819$

$\mathrm{m} \quad=\frac{f y}{0,8 \cdot f^{\prime} c}=\frac{340}{0,8 \cdot 25}=16$

$\rho_{\text {perlu }}=\frac{1}{m}\left(1-\sqrt{1-\left(\frac{2 \cdot m \cdot R n}{f y}\right)}\right)$

$=\frac{1}{16}\left(1-\sqrt{1-\left(\frac{2.16 \cdot 0,819}{340}\right)}\right)=0,00246$

Luas tulangan :

As $=\rho_{\text {perlu }}$ b . $d=0,00246.1000 .640=974,22 \mathrm{~mm}^{2}$

Dipakai tulangan pokok $\phi 16-200=1004,80 \mathrm{~mm}^{2}>$ As bagi $(\mathrm{OK})$

$$
=1004,80 \mathrm{~mm}^{2}>974,22 \mathrm{~mm}^{2}(\mathrm{OK})
$$


Jurnal Qua Teknika, Vol. 8 No. 1 Maret 2018

p-ISSN: 2088-2424; e-ISSN: 2527-3892

Fakultas Teknik Universitas Islam Balitar, Blitar

Http://qua.unisbablitar.ejournal.web.id; Email: quateknika@Gmail.com

Tri Hartanto dan Achendri M. Kurniawan. 2018. Perhitungan struktur dan volume bangunan abutment jembatan beton (Studi Kasus Jembatan Beton Bertulang di Desa Jolosutro Blitar). Jurnal Qua Teknika, (2018), 8 (1):1-10

\section{SIMPULAN}

Berdasarkan hasil dari penelitian ini, maka dapat ditarik kesimpulan sebagai berikut :

a. Daya dukung tanah $\mathrm{Q}_{\text {all }}=47,75 \mathrm{t} / \mathrm{m}^{2}$

b. Stabilitas guling $\mathrm{SF}=4,219>1$ ( terpenuhi dan sangat mendukung OKE )

c. Stabilitas eksentrisitas e $=-0829<0,4(\mathrm{OKE})$

Penulangan bagian - bagian struktur pada bangunan abutment :

1. Penulangan plat sandung $=$ Tulanganpokok $\phi 16-150$

$$
=\text { Tulangan bagi } \phi 16-125
$$

2. Penulangan plat konsul $=$ Tulanganpokok $\phi 19-200$

$=$ Tulanganbagi $\phi 12-200$

3. Penulangan tubuh abutment $=$ Tulanganpokok $\phi 22-150$ $=$ Tulangan bagi $\phi 12-150$

4. Penulangan dasar abutment $=$ Tulanganpokok $\phi 16-200$ $=$ Tulangan bagi $\phi 16-200$

\section{DAFTAR PUSTAKA}

Sutami. 1971. Konstruksi Beton Indonesia. Jakarta: Badan Penerbit Pekerjaan Umum.

Sagel, R. Kole. 1994. Pedoman Pengerjaan Beton. Jakarta: Erlangga.

Asroni, A. 2010. Struktur Beton I (Balok dan Plat Beton Bertulang). Yogyakarta: Graha Ilmu.

Departemen Pekerjaan Umum. 1982. Persyaratan Umum Bahan Bangunan Di Indonesia (PUBI - 1982). Bandung: Yayasan Lembaga Penyelidikan Masalah Bangunan.

Dipohusodo, I. 1994. Struktur Beton Bertulang. Jakarta: Gramedia Pustaka Utama.

Kusuma, G. H. 1997. Dasar-dasar Perencanaan Beton Bertulang. Jakarta: Erlangga.

Wahyudi, L. 1997. Struktur Beton Bertulang. Jakarta: Gramedia Pustaka Utama. 